EPJ Web of Conferences 33, 01003 (2012)

DOI: $10.1051 /$ epjconf/20123301003

(C) Owned by the authors, published by EDP Sciences, 2012

\title{
Estimating Renewable Energy Resources of Russia: Goals and Perspectives
}

S. Kiseleva ${ }^{1}$, J. Rafikova ${ }^{1}$ and V. Shakun ${ }^{1}$

${ }^{1}$ Laboratory of Renewable Energy Sources, Faculty of Geography, Lomonosov Moscow State University, 119991, Leninskie gory 1-19, Moscow, Russia

\begin{abstract}
During the last several years in some regions of Russian Federation one can observe a growing interest in renewable energy projects motivated by a necessity to have stable, affordable and autonomous energy sources. Besides, there has been an advance in legal initiatives designed to regulate the development of renewable energy sources in Russia. Some governmental regulations having for an object to stimulate this area, have already been accepted. The regulation contains the target value parameters of the output volume of the electric energy output volumes with the use of renewable energy sources (except hydroelectric power plants with the established capacity exceeding $25 \mathrm{MW}$ ). The work shows the results of resource estimating wind, solar, biomass energy resources for Russia, using GIS methods, which allow one to provide more exact predictions for the energy development, and therefore to prove investments and to pass to working out the equipment design of energy plants based on renewable energy sources. Current matters are relating to opportunities and perspectives of renewable energy sector in Russia.
\end{abstract}

Despite of seeming security with resources of organic fuel, even nowadays in Russia there are preconditions and extensive niches for effective application of renewable; first of all, in the areas remote from centralized systems of power supply. These niches can be essentially expanded in case of purposeful implementation of the administrative decisions accepted recently on economy power efficiency increase and stimulation of renewable sources development. According to the Government's of Russian Federation Order [1] it is offered to reach a contribution of renewables to electricity generation (without hydroelectric power stations in capacity more than $25 \mathrm{MW}$ ) at level of $4,5 \%$ in Russia by 2020 , or to place operation power installations on renewables in total capacity more than $20 \mathrm{GW}$. By RusHydro [11] estimates, in order to reaching this purpose it is necessary to put the following types of renewable energy power installations into by 2020 (tab. 1).

Table 1. Predicted volumes of renewable energy power installations input, $M W$ (RusHydro data) [11]

\begin{tabular}{|l|l|l|l|l|}
\hline Power installations (<25 MW) & $\mathbf{2 0 0 5}$ & $\mathbf{2 0 1 0}$ & $\mathbf{2 0 1 5}$ & $\mathbf{2 0 2 0}$ \\
\hline Small and micro hydro & 680 & 850 & 2430 & 4800 \\
\hline Wind & 12 & 120 & 1500 & 7000 \\
\hline Geothermal & 71 & 90 & 300 & 750 \\
\hline Biomass & 1413 & 2800 & 5000 & 7850 \\
\hline Tidal & 1,5 & 1,5 & 12 & 4500 \\
\hline Solar & 0,02 & 0,02 & 1,5 & 12,1 \\
\hline Wave power and other sources & 0 & 0 & 20 & 250 \\
\hline Total & 2177,52 & 3861,52 & 9243,5 & 24912,1 \\
\hline $\begin{array}{l}\text { Share of renewables in electrical energy production } \\
\text { (excluding large hydropower), \% }\end{array}$ & $\mathbf{0 , 9}$ & $\mathbf{1 , 5}$ & $\mathbf{2 , 5}$ & $\mathbf{4 , 5}$ \\
\hline
\end{tabular}

Thus there are some features in Russia, comparing with the European countries, USA and others, where renewable sources have already found a wide usage: the systems of centralized power supply cover only 1/3 of the Russian Federation territories 
(Figure 1); for $70 \%$ of the territory with the population about 20 million people power supply of consumers is carried out mainly by means of the independent power installations working on expensive imported liquid fuel or using local resources (coal, wood fuel, peat, etc.); only about $50 \%$ of the cities and about $35 \%$ of rural settlements are connected to the gas mains; many consumers, including those, who are located in a zone of centralized power supply, usually prefer to use own electro- and heat supplies sources in the existing economic circumstances, and that in some cases results in irrational use of organic fuel and the ecological situation deterioration [2].

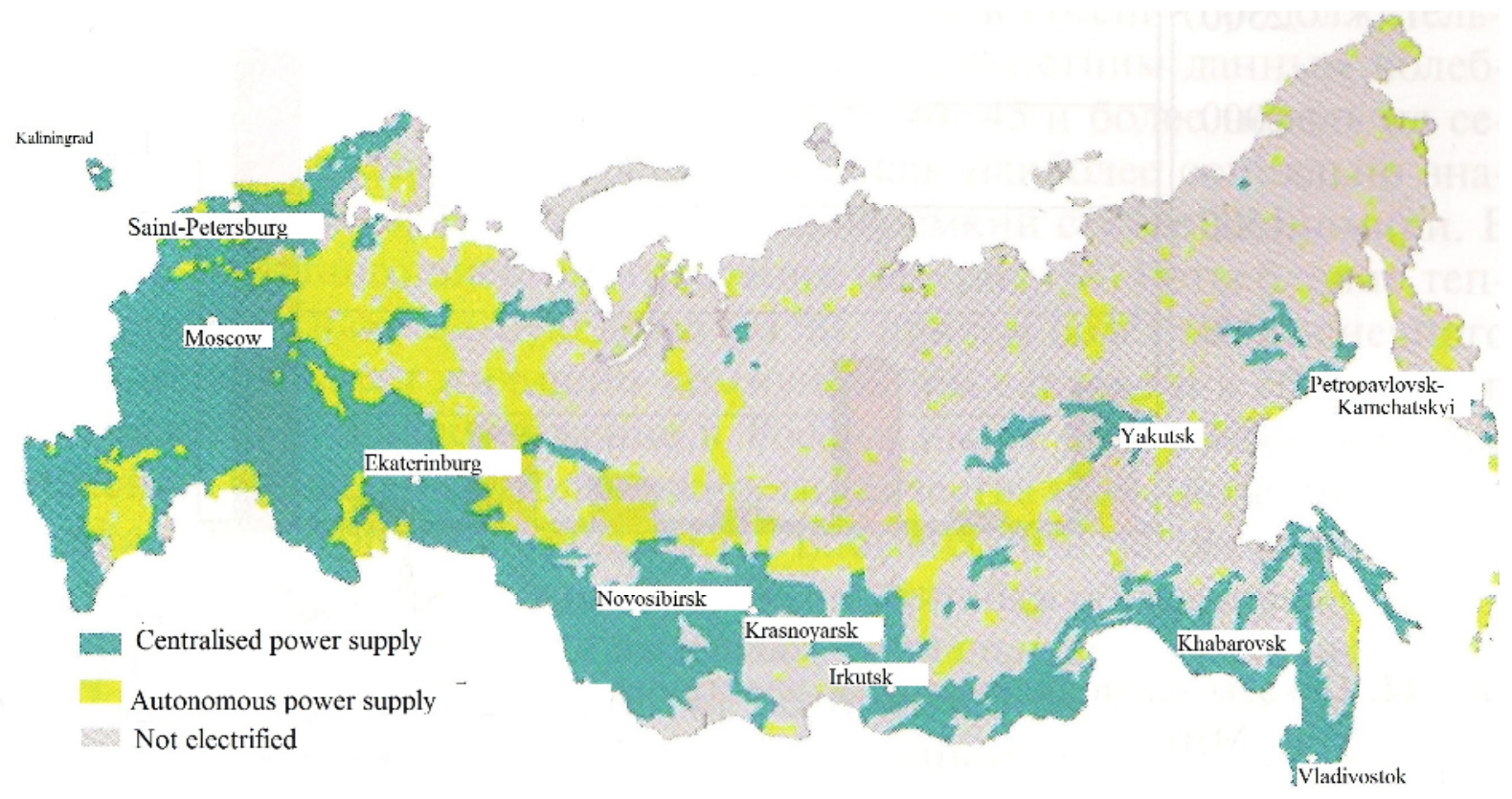

Fig. 1. The centralized and autonomous power supply on the territory of Russia. [2]

According to the Russian Federal Service of State Statistics and Energy Research Institute of the Russian Academy of Sciences, the number of refusals on new consumers connection to power supply systems for the technological reasons is increasing. So, in 2007 more than 2,3 GW of total capacity were refused to connect (Figure 2). The most difficult situation is in the south of the European part of the country where about $30 \%$ of demands for connection were rejected.

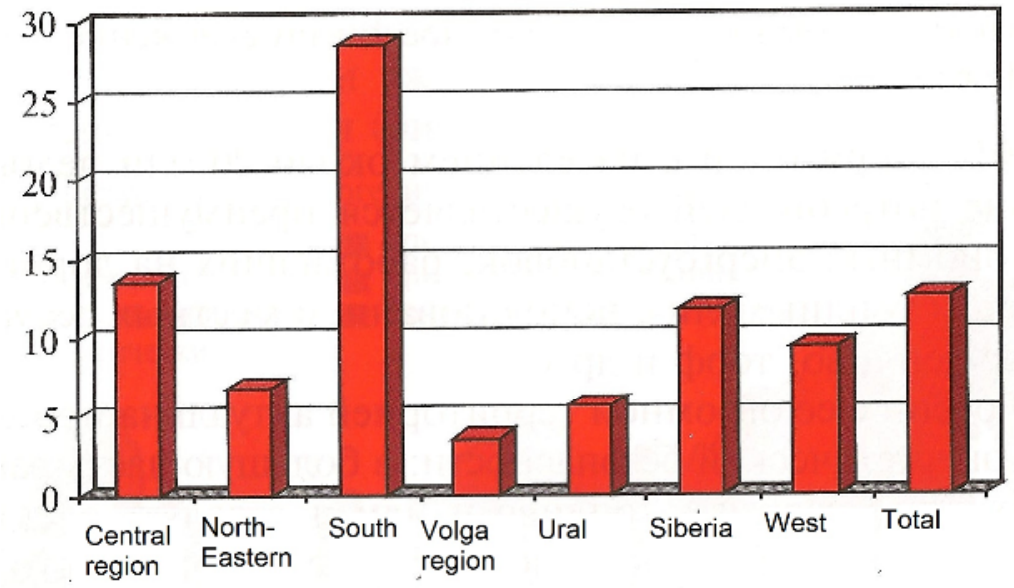

Fig. 2. Refusals on connection to electric networks by regions of Russia, MW [2]

In the current circumstances the autonomous power in Russia is developing faster than centralized. The input of small power plants during the period from 2001 to 2007 was about 13,4 GW, while for the same period the input of large power plants was only $9,6 \mathrm{GW}$ [3]. It is clear, that the power complex of the country needs serious modernization which can be carried out only with active state and business participation. [2]

Now, after the long period of unreasonable expectations of initiatives on development of renewable power from the ministries and departments of Russia, we can observe an interest for renewable energy systems at the regional level. Such regions are the Krasnodar Krai and Stavropol Krai, the Arkhangelsk region, the Republics of Karelia, Bashkiria, Tyva, Buryatiya. Realization of different scaled projects at these regions and is connected with a number of factors, including regional specifics - from natural energy resources to social and demographic and power balances. To consider, estimate and analyse all these factors we need to create an extensive arrays of information, and also use analysing tools which would allow to collect, operatively modernize, transform and display these data files, to receive reasonable estimates on their basis and to perform calculations. 
At the same moment it is necessary to consider that generally the user is interested in complex estimations on different types of power sources, because the most effective can be the use of hybrid power installations, or creation of several installations (stations) on various types of energy. Due to the integrated approach of the specified problem of renewable power, and to the regional aspect it is possible and actual to use geoinformation technologies.

The analysis of foreign GIS on renewables $[5,6,7,8,9,10]$ allowed us to present general tasks and possible ways of their decision. But owing to specific features of renewable power in Russia there is a question of creation GIS of renewable energy sources for Russian Federation. The main specific is the extensive zone of autonomous electro - and heat supplies, where the greatest interest in renewable energy use is observed. And also, the analysis is mostly actual at the regional and local level.

Geoinformation system «Renewable Energy Sources of Russia» is carried out by Faculty of Geography, Lomonosov Moscow State University and the Joint Institute for High Temperatures of the Russian Academy of Sciences within the Scientific and educational center "Renewable energy sources". It has become one of the first GIS-projects on renewable energy in Russia. [4]

The structure of developing GIS is presented on the following scheme (Figure 4).

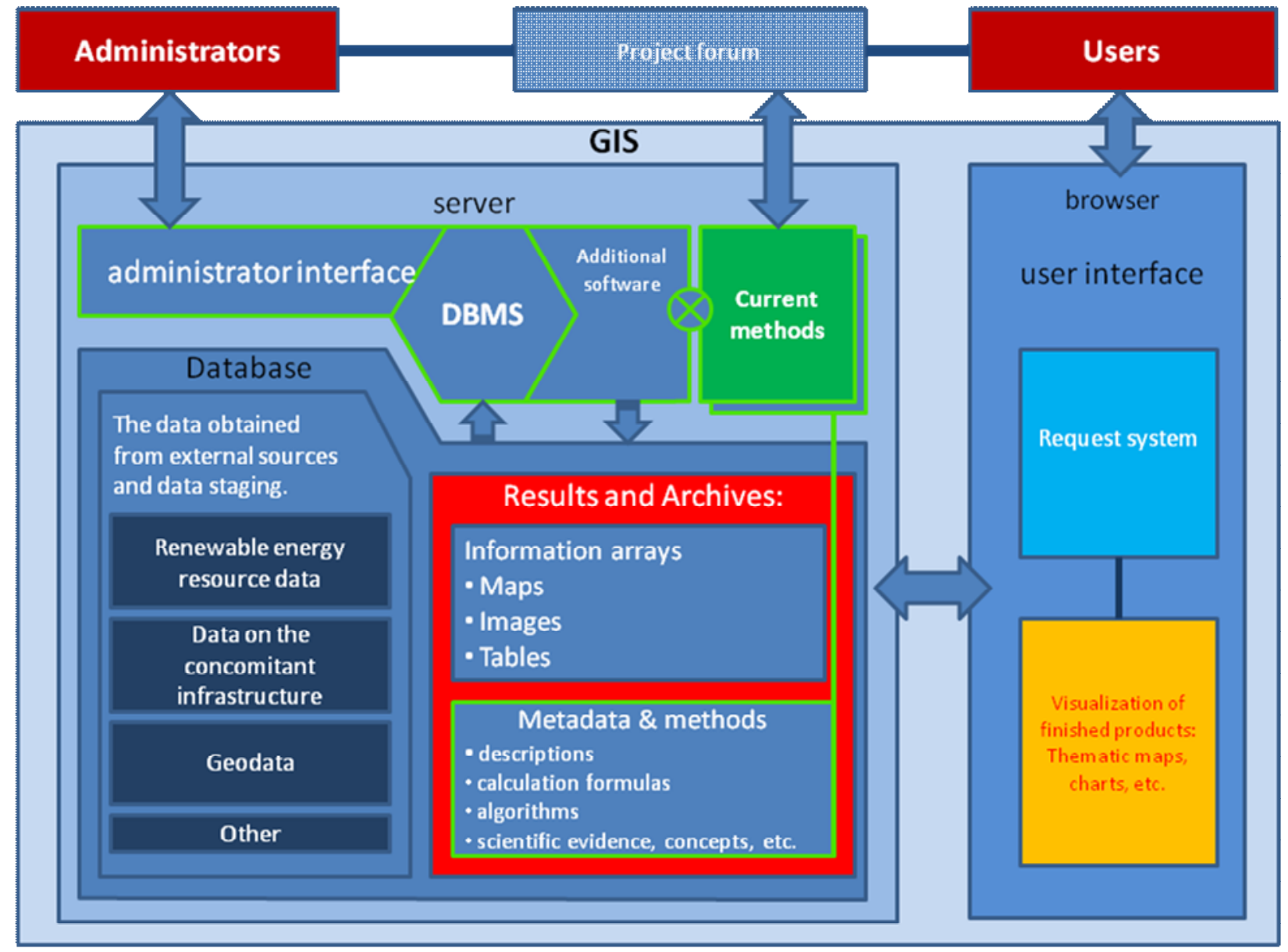

Fig. 3. Structured scheme of GIS-project

Scheme of GIS-project in general terms is a system of information processing cycle, as well as the structure of the interaction between developers of the project and users through GIS.

Essentially, the work of this scheme following: a user who is interested in renewable energy issues user comes to the site of the project familiar with the subject and through the authorization accesses desired content. Then, if you need more information on this site, you will be introduced to implement the request form for further search (by now the system is under development and user requests are coming directly to e-mail). It is also worth noting that in the stage of information processing developers can quickly change the method of fragments, making up the optimal choice using the current adjustment. In general, the technique may lie in the structure of the GIS separately and in the form of metadata as static data. But considering its direct effect on the processing of information, it is advisable to consider this block is twofold. On the one hand, it is a collection of definitions and concepts that are fixed at the moment, on the other hand, it is implemented on the basis of the forum, flexible, interactive system of ideas and initiatives priority within the main design paradigm.

Thus, the block of methods facilitates rapid determination of the correct vector search, allowing you to choose an algorithm tailored to each specific task.

The following data are currently presented on the site of the project:

1. Maps of solar, wind and bioenergy characteristics distribution, and also maps of some technical characteristics (for example, a share of hot water supply loading by means of solar water-heating installations of setted capacity).

2. Information on objects and projects of renewable power in Russia with their short description (Figure 4). 


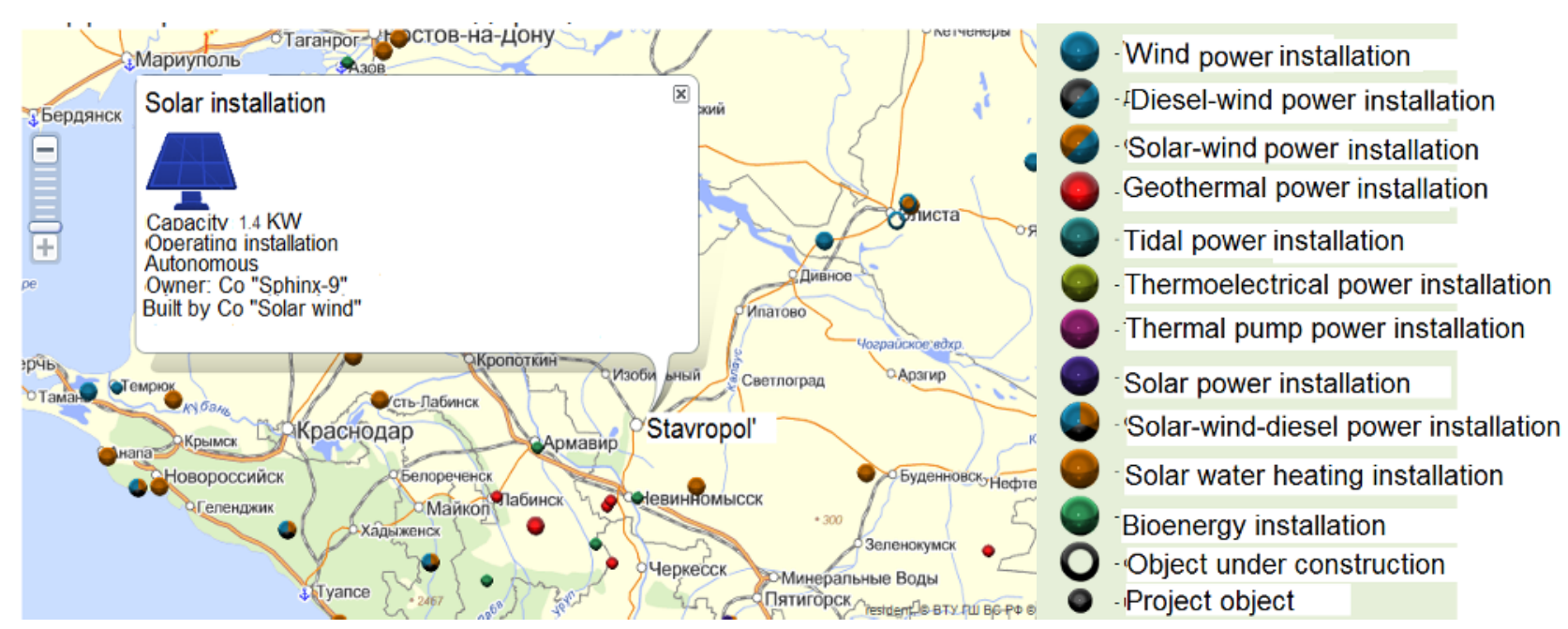

Fig. 4. The fragment of the map of renewable power operating and projected installations for the Russian Federation territory.

3. Tables with characteristics of renewable energy sources (for bio- and geothermal energy sources).

4. $\quad$ Procedures of some renewable energy characteristics calculations.

5. The atlas of solar energy resources for the Russian Federation territory [12].

Some of the renewable energy sources GIS of Russia products are maps of solar, wind and bioenergy sources made both for all the territory of country (Figure 5), and for separate regions.

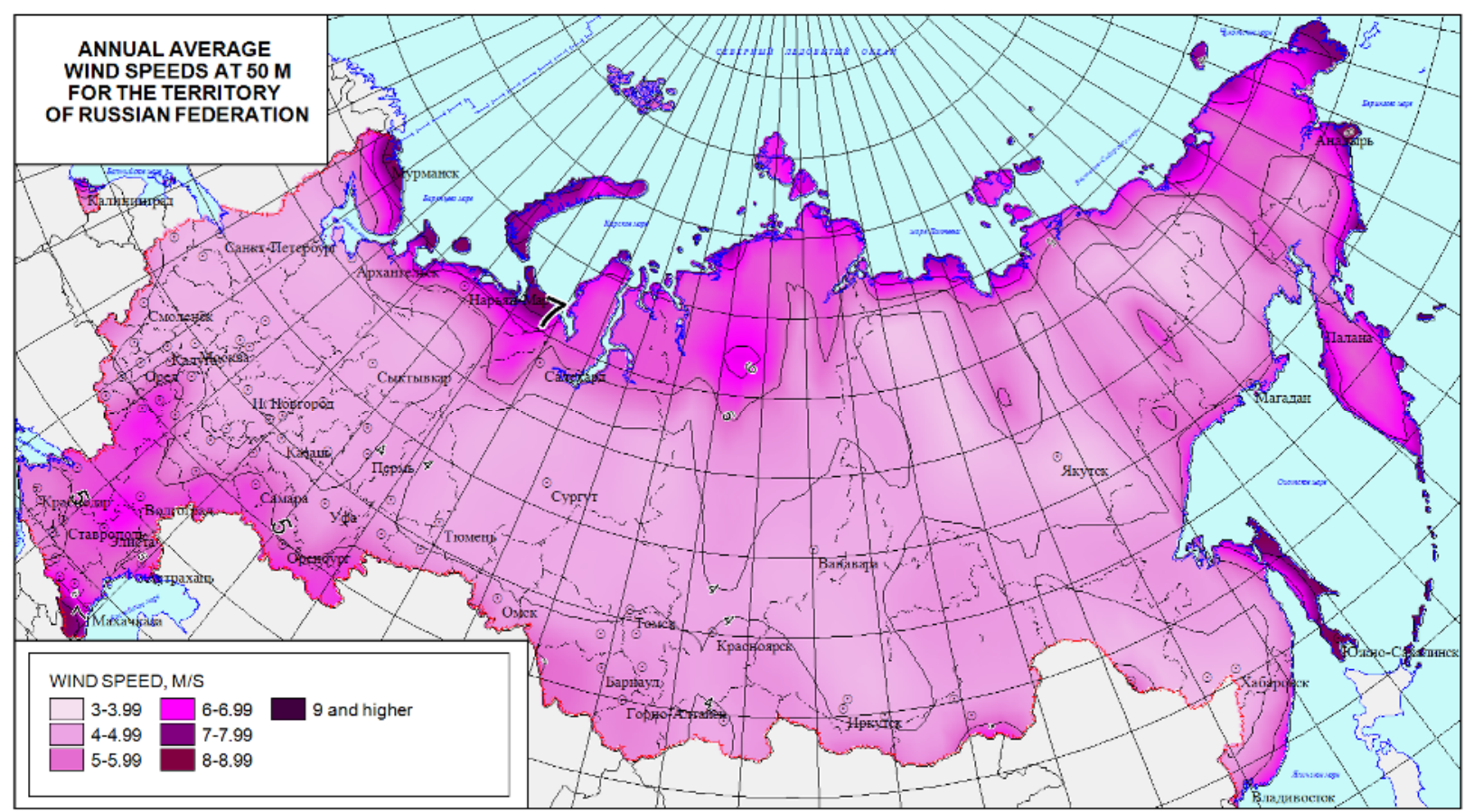

Fig. 5. Distribution of average wind speeds at height of $50 \mathrm{~m}$ for the Russian Federation territory.

Calculations of electric power output by standard wind installations are made for some regions (that is the technical potential of renewable energy) (Figure 6). 


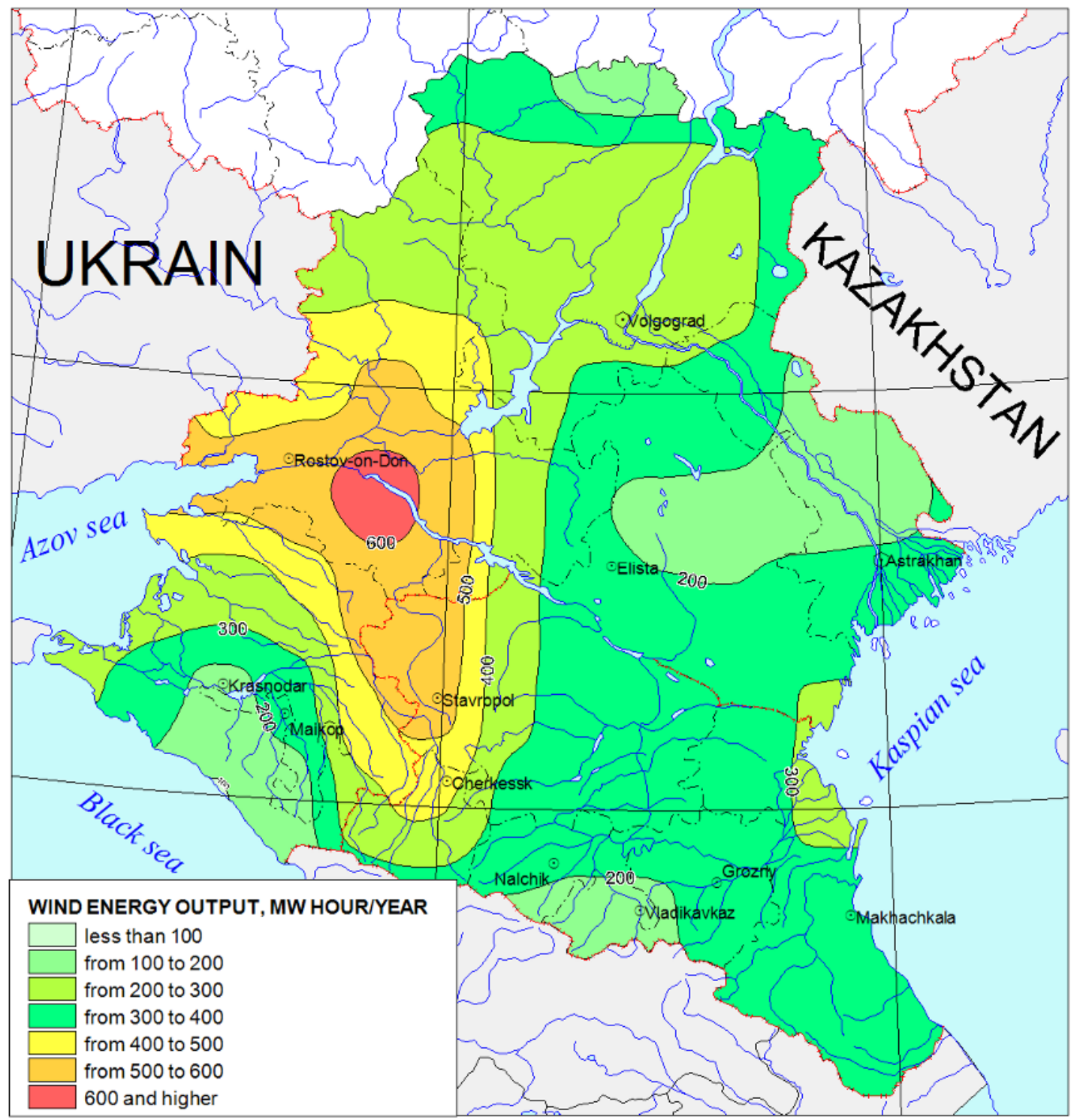

Fig. 6. Distribution of wind energy output of VESTAS V44-50 wind turbine for the South of Russia.

\section{Conclusions}

1. In the European countries development of renewable energy sources geoinformatical systems is demanded in connection with rapid development of renewable power. Though this requirement is less in Russia, in recent years renewable power in our country has also been designated and now special interest is arising at the regional level, where the lack of information on renewable energy sources affects and software products can be found, allowing this information to be analyzed.

2. For Russia the most actual is to develop renewable power in the territories of independent power supply. Interest mostly is shown from regions.

3. The analysis of foreign GIS gives a methodical basis for development of such product in Russia, however there are specifics of development renewable power in Russia and also own approaches, including methods of estimates, mapping and analysis.

4. The potential estimations of renewable energy sources have to be based on drawing up and thorough analysing of multiscaled dynamic cartographic materials.

5. Developed Renewable energy sources GIS of Russia can be demanded by individuals, the municipal and federal state organizations of power and ecological profile, design organizations, research and educational institutions.

This work was financially supported by the national program «Scientific and educational brainpower of innovation Russia» on 2009-2013, contract № 14.740.11.0096.

\section{References}

1. The order of Russian Federation Government from January 08, 2009, №1-r. 
2. V.E.Fortov, O.S.Popel, Power in the modern world. (Publishing house «Intellekt», 2011).

3. S.P.Filippov, Small power industry of Russia, Power system, 8 (2009)

4. $\quad$ www.gis-vie.ru (13.04.2012)

1. Www.vtenergyatlas.com (13.04.2012)

2. http://www.nrel.gov/gis/about.html (13.04.2012)

3. www.3tier.com (13.04.2012)

4. http://eosweb.larc.nasa.gov/sse/ (13.04.2012)

5. http://wrdc.mgo.rssi.ru (13.04.2012)

6. http://solargis.info/imaps/ (13.04.2012)

7. www.rushydro.ru/ (13.04.2012)

8. http://gis-vie.ru/index.php?option=com_content\&view=article\&id=127\&Itemid=58 (13.04.2012) 